\title{
Centrally Acting Incapacitants
}

\section{GENERAL}

\section{Introduction}

An incapacitant is a chemical agent which produces a disabling condition that persists for hours to days after exposure to the agent (unlike that produced by riot control agents). Medical treatment will facilitate more rapid recovery, but may not be essential in some cases. Specifically, the term has come to mean those agents that are:

- highly potent (an extremely low dose is effective) and logistically feasible.

- able to produce their effects by altering the higher regulatory activity of the CNS.

- of a duration of action lasting hours or days, rather than of a momentary or fleeting action.

- not seriously dangerous to life except at doses many times the effective dose.

- not likely to produce permanent injury in concentrations which are militarily effective.

These criteria eliminate many drugs that might otherwise be considered as incapacitants. Opiates and strong sedatives are too dangerous on account of their low margin of safety and tranquillisers cause little actual loss of performance capability. Many compounds have been considered as incapacitants and medical staff must be alert to detect and report any unusual clinical appearances.

Two categories will be discussed: CNS depressants (e.g. BZ) and CNS stimulants (e.g. LSD). Although cannabinols and psylocibin, for instance, have been considered in the past, their effective dose is too high for these to be regarded as likely agents for use in the field.

\section{CNS Depressants}

CNS depressants produce their effects by interfering with neurotransmission. An example of this type of agent is 3quinuclidinyl benzilate (BZ), which blocks the muscarinic action of acetylcholine both peripherally and centrally. In the CNS, anticholinergic compounds disrupt the cognitive functions such as memory, problem solving, attention and comprehension. Relatively high doses produce toxic delirium which destroys the ability to perform any military task.

\section{CNS Stimulants}

CNS stimulants cause excessive neuronal activity by facilitating neurotransmission. The effect is to overload the cortex and other higher regulatory centres making concentration difficult, causing indecisiveness and inability to act in a sustained purposeful manner. A well known drug which acts in this way is D-lysergic acid diethylamide (LSD); similar effects are sometimes produced by large doses of amphetamines.

\section{Detection}

In general, no automated stand-off point detector systems exist for agents in this category and only limited field laboratory methods exist for the identification of such agents in environmental samples. Initial diagnosis rests almost entirely upon clinical acumen, combined with whatever field intelligence may be available.

\section{Protection}

It is likely that such agents will be dispersed as solid aerosols by either pyrotechnic or explosive munitions, using the respiratory tract as a portal of entry; the use of the respirator is essential. Some agents may be absorbed percutaneously and therefore full individual protective equipment may be required.

\section{Decontamination}

Removal of contaminated clothing and complete cleansing of the skin with soap and water should be accomplished at the earliest opportunity. Symptoms may appear as late as $36 \mathrm{~h}$ after percutaneous exposure, even if the skin is washed within an hour. In fact, a delay in onset of several hours is typical. This time should be used to prepare for the possibility of an outbreak of effects 6 - $24 \mathrm{~h}$ after the attack.

\section{General Management}

Following the occurrence of a suspected chemical attack with incapacitating agents, the medical officer should be prepared to take the following steps:

- resistant or disoriented casualties will need to be disarmed and may have to be restrained during evacuation and whilst in the medical treatment facility.

- once the diagnosis of a nerve agent or other lethal substance has been ruled out, the principal signs and symptoms to consider are those shown in Table 9. 


\begin{tabular}{|l|l|}
\hline $\begin{array}{l}\text { Signs and Symptoms } \\
\text { Restlessness, dizziness or giddiness; failure } \\
\text { to obey orders, confusion, erratic behaviour; } \\
\text { stumbling or staggering; vomiting. }\end{array}$ & $\begin{array}{l}\text { Possible } \\
\text { Anticholinergics (eg. BZ), indoles (eg. } \\
\text { LSD), cannabinols (eg. Marihuana), } \\
\text { anxiety reaction, other intoxications (eg. } \\
\text { alcohol, bromides, barbiturates, lead). }\end{array}$ \\
\hline $\begin{array}{l}\text { Dryness of mouth, tachycardia at rest, } \\
\text { elevated temperature, flushing of face; } \\
\text { blurred vision, pupillary dilation; slurred or } \\
\text { nonsensical speech, hallucinatory } \\
\text { behaviour, disrobing, mumbling and } \\
\text { picking behaviour, stupor and coma. }\end{array}$ & Anticholinergics. \\
\hline $\begin{array}{l}\text { Inappropriate smiling or laughter, irrational } \\
\text { fear, distractability, difficulty expressing self, } \\
\text { perceptual distortions; labile increase in } \\
\text { pupil size, heart rate, blood pressure. } \\
\text { Stomach cramps and vomiting may occur. }\end{array}$ & $\begin{array}{l}\text { Indoles. (Schizophrenic psychosis may } \\
\text { mimic in some respects). }\end{array}$ \\
\hline $\begin{array}{l}\text { Euphoric relaxed, unconcerned day- } \\
\text { dreaming attitude, easy laughter; } \\
\text { hypotension and dizziness on sudden } \\
\text { standing. }\end{array}$ & Cannabinols. \\
\hline $\begin{array}{l}\text { Tremor, clinging or pleading, crying; clear } \\
\text { answers, decrease in disturbance with } \\
\text { reassurance; history of nervousness or } \\
\text { immaturity, phobias. }\end{array}$ & Anxiety reaction. \\
\hline
\end{tabular}

In a large-scale attack, the diagnosis will be simplified by the epidemiological distribution of the casualties. It is better to look for characteristics common to all or most casualties, than to be overly impressed with atypical features. For example, some anticholinergics are capable of causing marked disorientation, incoherence, hallucinations and confusion (the pathognomonic features of delirium) with very little, if any, evidence of peripheral autonomic effect (such as tachycardia and dilated pupils). This should not dissuade the medical officer from considering the likelihood of a centrally predominant anticholinergic being the causative agent, since very few other pharmaceutical classes can produce delirium in militarily effective doses. The disturbance produced in indoles (such as LSD) or the cannabinols (such as marihuana extracts) is not really delirium, because the casualties remain receptive to their environment and can comprehend quite well, even though they may have great difficulty reacting appropriately. Differential diagnosis should consider atropine overdose, malingering, heat or battle stress.

\section{CNS DEPRESSANTS - BZ (3-QUINOCLINIDINYL BENZILATE) AND SIMILAR COMPOUNDS}

\section{Detection}

In general, no automated stand off point detector systems exist for these agents. However, field laboratory methods are available to isolate and identifiy BZ, e.g. in the Draeger ${ }^{\mathrm{TM}}$ Tube System.

\section{Protection}

Protection is given by the respirator, NBC suit, foot protection and gloves.

\section{Properties}

$\mathrm{BZ}$ and its analogues are glycollic acid esters. Some members of the group are liquid at ambient temperatures but $\mathrm{BZ}$ is a stable white crystalline powder that is only slightly soluble in water. These agents are metabolised primarily in the liver and excreted by the kidneys.

\section{Mechanism of Action}

BZ (3-quinuclidinyl benzilate) is an anticholinergic agent that at single doses of less than $1 \mathrm{mg}$ produces delirium lasting several days. In this respect, it resembles the well known belladonna alkaloids atropine and scopolamine, except that it is more potent and its effects last longer. The safety margin (ratio of lethal to incapacitating dose) in man is estimated to be at least 30 .

BZ is effective by all routes of administration, but its effectiveness percutaneously (when mixed with a suitable solvent) is limited, so that route is not likely to be used. However there are other related compounds which are effective percutaneously. BZ and other glycollates produce their effects within the nervous system in the 
same way as atropine and scopolamine, that is by interfering with cholinergic transmission at muscarinic sites, both in the peripheral autonomic nervous system and in the brain and spinal cord. Because of the wide distribution of these sites, measurable effects upon almost every phase of neural regulation may be observed. It readily crosses the blood-brain barrier and is distributed to all areas of the brain and spinal cord.

After exposure to an effective dose, mild peripheral effects of $\mathrm{BZ}$ occur within $1 \mathrm{~h}$ and central effects occur after about $4 \mathrm{~h}$. The central effects peak at $8-10 \mathrm{~h}$ and last 24 $48 \mathrm{~h}$. Some other compounds in this group may take longer for their effects to develop and to disappear. Doubling the dose prolongs the duration of severe central effects by about $40 \mathrm{~h}$ and shortens the onset time of severe effects to about $1 \mathrm{~h}$.

\section{Signs and Symptoms}

Small doses of BZ cause sleepiness and diminished alertness. Diagnosis can be made by noting increased heart rate, dry skin and lips, drowsiness and progressive signs of intoxication in the untreated individual as follows:

- 1-4 h: tachycardia, dizziness, ataxia, vomiting, dry mouth, blurred vision, confusion, sedation progressing to stupor.

- 4-12 h: inability to respond to the environment effectively or to move about.

- 12-96 h: increasing activity, random unpredictable behaviour with delusions and hallucination; gradual return to normal 48 to $96 \mathrm{~h}$ after exposure.

\section{Treatment}

For most casualties, symptomatic treatment is all that will be necessary. Firm restraint (when necessary) and a friendly attitude are called for especially in dealing with casualties capable of walking. All dangerous objects must be removed and anything likely to be swallowed should be kept away from the subject as bizarre delusions may occur. The most important single medical consideration is the possibility of heat stroke. Clothing should be removed if the temperature is greater than $25^{\circ} \mathrm{C}$. If the body temperature is greater than $39^{\circ} \mathrm{C}$, vigorous cooling is indicated. The casualty should be placed in the shade and air allowed to circulate. Water may be sprayed on the casualty to aid cooling, ice should not be applied to the skin.

Physostigmine is an antidote to $\mathrm{BZ}$ but should be reserved for casualties who appear to be in danger. Physostigmine is minimally effective during the first $4 \mathrm{~h}$ after exposure, but is very effective after $4 \mathrm{~h}$. An injection of 2-3 mg will be required to alleviate the symptoms. Repeated injections at intervals of approximately $15 \mathrm{~min}$ to $1 \mathrm{~h}$ may be required to build up a sufficient level. Once a desirable effect is achieved, it should be maintained by slow intravenous injection or infusion. Doses of $2-4 \mathrm{mg}$ every 1 or $2 \mathrm{~h}$ may be required. The dose should be titrated against symptoms with gradual tapering of the dose as the effect of the poisoning runs its course. This may vary from a few hours to several days. The temptation to substitute a slow IV infusion for intramuscular injections should be tempered by the awareness that IV infusion may lead to nerve-agent-like bradycardia and too rapid infusion might lead to arrhythmias, excessive secretions (to the point of compromising air exchange), and convulsions. Oral dosing should replace intravenous therapy as soon as possible ( 2 to $5 \mathrm{mg}$ every 1 to $2 \mathrm{~h}$ ).

7-methoxytocrine (7-MEOTA) can also be used as an antidote for BZ. To eliminate BZinduced signs and symptoms, one tablet (100 mg) 7-MEOTA should be used. In the case of severe poisoning, intramuscular administration (50 mg 7-MEOTA lactate in $5 \mathrm{ml}$ ) is preferred; the dose is required every $8 \mathrm{~h}$ to reach a stable therapeutic level of this antidote. During this dose regimen, no side effects are expected.

Peripherally acting drugs which do not cross the blood-brain barrier - such as pyridostigmine, neostigmine and pilocarpine - are ineffective antagonists of the central effects of BZ and should not be used in place of physostigmine.

\section{CNS STIMULANTS-LSD (D-LYSERGIC ACID DIETHYLAMIDE)}

\section{Properties}

LSD is solid at normal temperatures and is soluble in water. It is a very difficult agent to disseminate and consequently is likely to be used by an enemy only in a clandestine manner.

\section{Detection}

There is no device available for detecting this agent in the field.

\section{Protection}

No personal protection is available against clandestine attack, but it seems probable that only small quantities of food or water could be contaminated. Good security of the food and water supply are therefore required.

\section{Mechanism of Action}

Very small doses (for example $50 \mu \mathrm{g}$ per person) are capable of inducing a psychotic state in man, but the precise mechanism of action is not yet known. LSD has been shown to facilitate neural activity in the reticular activating system of the brain stem. It appears to interfere with the normal filtering action of this system, permitting sensory input to reach higher integrative centres without regard to its importance or relevance. The result is a decrease in the 
ability of the brain to process information selectively and in logical sequence.

\section{Pathophysiology}

LSD is the most potent of the biologically active indole compounds, as little as $50 \mu \mathrm{g}$ being required to produce dramatic psychological changes. Doses of 2 to $5 \mathrm{mg}$ have been taken without permanent sequelae, and animal studies suggest that much higher doses may be tolerated, however, convulsions may occur at doses above $2 \mathrm{mg}$. LSD may be inhaled or ingested. Initial effects appear within a few minutes of inhalation or within 30 to $60 \mathrm{~min}$ of ingestion. Maximum effects are reached within 2 to $3 \mathrm{~h}$ and gradually subside over the next 4 to $8 \mathrm{~h}$. The half-life in human plasma is about $3 \mathrm{~h}$. Tolerance is acquired rapidly on repeated exposures at daily intervals, but is short-lived. LSD appears to interact with endogenous neurotransmitters such as serotonin with which it shares the common feature of an indole nucleus. It is metabolised by the liver and excreted through the kidneys.

\section{Signs and Symptoms}

The clinical manifestations of LSD intoxication often include an early stage of nausea followed 45-60 min after dosage by a confused state, in which delusions and hallucinations are common but not always experienced. There is some evidence that the effects may be held off, at least for a time, by determination to continue duty and that the presence of non-intoxicated personnel enables affected subjects to maintain contact with reality.

Subjects intoxicated with LSD show evidence of sympathetic stimulation (rapid heart rate, sweating palms, apillary enlargement, cold extremities) and mental excitation (nervousness, trembling or spasms, anxiety, euphoria and inability to relax or sleep). Hyperthermia has been reported. Subjectively, feelings of tension, heightened awareness, exhilaration, kaleidoscopic imagery, emotions of every type, hilarity and exultation are character-istic. Paranoid ideas and more profound states of terror and ecstasy may also occur, especially in highly suggestible individuals. True hallucinations are rare, as is homicidal or suicidal behaviour.

\section{Treatment}

No true antagonist to the indoles is known. The best treatment at present for LSD intoxication is the administration of diazepam 10-20 $\mathrm{mg}$ intravenously or intramuscularly. Chlorpromazine has also been suggested but does not appear to have any advantage over diazepam.

\section{Course and Prognosis}

The question of long term effects is still unresolved, but single exposures to doses in the clinical range (0.1 to $1.0 \mathrm{mg}$ total dose) appear unlikely to cause any permanent biological damage. 